\title{
Adnexal Torsion in Pregnancy after Assisted Repro- duction - Case Study and Review of the Literature
}

\author{
Adnex-Torsionen in der Schwangerschaft nach künstlicher Befruchtung
}

Authors

Affiliations
D. Spitzer ${ }^{1}$, B. Wirleitner ${ }^{2}$, H. Steiner ${ }^{3}$, N. H. Zech ${ }^{2}$

1 IVF Zentren Prof. Zech Salzburg, Salzburg, Austria

${ }^{2}$ IVF Zentren Prof. Zech Bregenz, Bregenz, Austria

${ }^{3}$ Universitätsklinik für Frauenheilkunde und Geburtshilfe, Landeskrankenhaus Salzburg,

Paracelsus Medizinische Privatuniversität, Salzburg, Austria
Key words

- Adnexal torsion

- controlled ovarian hyperstimulation

- assisted reproduction

- laparoscopic derotation

Schlüsselwörter

- Adnex-Torsion

- kontrollierte ovarielle Hyperstimulation

- assistierte Reproduktion

- laparoskopische Derotation received 11.4.2012 revised 15.5.2012 accepted 29.5.2012

\section{Bibliography}

DOI http://dx.doi.org/ 10.1055/s-0032-1315186 Geburtsh Frauenheilk 2012; 72: 716-720 @ Georg Thieme Verlag KG Stuttgart · New York . ISSN 0016-5751

\section{Correspondence} Dr. Dietmar Spitzer

IVF Zentren Prof. Zech Salzburg Innsbrucker Bundesstraße 35 5020 Salzburg

Austria

d.spitzer@salzburg.ivf.at

\section{Abstract \\ v}

Purpose: Aim of the study was to investigate the incidence, progress, management and outcome of adnexal torsion after controlled ovarian hyperstimulation in embryo transfer cycles.

Materials and Method: A retrospective analysis was done of 1007 patients of a private IVF centre. The literature on adnexal torsion is reviewed.

Results: In the literature, the incidence of adnexal torsion after assisted reproductive technologies (ART) is given as around $0.2 \%$. A significant increase of up to $33 \%$ has been reported for cases with additional ovarian hyperstimulation syndrome (OHSS) and in pregnant women. In our retrospective analysis of 1007 women (incidence $0.46 \%$ ) with 1411 fresh embryo transfer cycles, we found an incidence of $0.35 \%$ per embryo transfer. All adnexal torsions were treated by laparoscopic derotation to preserve fertility. All 5 cases with torsion were pregnant, 2 patients had mild OHSS. We recorded 3 term deliveries, 1 induced abortion for sirenomelia, and 1 missed abortion. Conclusion: Adnexal torsion must be kept in mind after hyperstimulation and embryo transfer, especially when pregnancy or OHSS is also present. With early diagnosis, it should be possible to preserve fertility using laparoscopic derotation.

\section{Introduction \\ $\nabla$}

With an incidence of $3 \%$, adnexal torsion is a common cause of emergency gynaecological procedures [1]. The symptoms are mostly unspecific and diagnosis is therefore not simple. Early diagnosis is essential to preserve organ function and fertility. The increased use of assisted reproductive technologies such as controlled ovarian hy-

\section{Zusammenfassung \\ $\nabla$}

Fragestellung: Häufigkeit, Verlauf, Therapie und Outcome von Adnex-Torsionen nach kontrollierter ovarieller Hyperstimulation in Embryotransfer-Zyklen.

Material und Methodik: Literatursichtung und retrospektive Untersuchung von 1007 Patientinnen eines privaten IVF-Zentrums.

Ergebnisse: In der Literatur wird die Inzidenz von Adnex-Torsionen nach ART mit maximal 0,2\% angegeben. Ein deutlicher Anstieg bis auf 33\% wird bei gleichzeitigem OHSS und einer Schwangerschaft beschrieben. In unserer retrospektiven Analyse an 1007 Frauen (Inzidenz 0,46\%) in 1411 frischen Embryotransfer-Zyklen konnten wir eine Inzidenz von 0,35\% pro Embryotransfer beobachten. Alle Adnex-Torsionen konnten mittels laparoskopischer Derotation fertilitätserhaltend behandelt werden. Alle 5 Patientinnen waren schwanger, in 2 Fällen trat ein leichtes OHSS auf. Drei Termingeburten stehen 1 Abort-Induktion wegen Sirenen-Malformation und 1 Missed Abortion gegenüber.

Schlussfolgerung: An Adnex-Torsionen muss nach Hyperstimulation und Embryotransfer gedacht werden, vor allem, wenn eine Schwangerschaft eintritt oder zusätzlich ein OHSS besteht. Bei rechtzeitiger Erkennung sollte durch Laparoskopie und Derotation die Erhaltung der Fertilität möglich sein.

perstimulation (COH), in vitro fertilisation (IVF) and intracytoplasmic sperm injection (ICSI) has led to an increase in the risk of adnexal torsion, particularly in pregnant women or women with ovarian hyperstimulation syndrome (OHSS). Mashiach et al. studied adnexal torsion in 201 women with OHSS over a period of 10 years and reported an incidence of $2.3 \%$ in nonpregnant women and an incidence of $16 \%$ in pregnant 
women [2]. The differential diagnosis of adnexal torsion is particularly difficult in combination with OHSS or pregnancy, as abdominal pain, nausea and vomiting can be presenting symptoms of hyperstimulation or pregnancy but also of adnexal torsion. The aim of our review article is to draw attention to this complication of assisted reproductive technology (ART) using case studies from our retrospective analysis of 1411 cases. Together with a review of the literature, we wish to emphasise the importance of early diagnosis for decision-making to preserve fertility.

\section{Materials and Method}

\section{$\nabla$}

The incidence of adnexal torsion was retrospectively analysed in 1007 patients (1411 fresh embryo transfer cycles) who attended our private IVF centre between January 2006 and April 2011. A questionnaire was used to investigate the course and outcome of the pregnancy in 571 clinical pregnancies (pregnancy rate per embryo transfer $40.5 \%$ ) including any maternal complications. The data of 461 births (birth rate $32.7 \%$ ) after ART was collected. Adnexal torsion occurred in 5 cases and each case is presented below.

\section{Case Reports \\ $\nabla$}

\section{Case 1}

A 35-year-old woman was stimulated prior to undergoing her 1st ICSI treatment which she required because of asthenozoospermia of her partner. Pituitary down-regulation consisted of long protocol (LP) with a GnRH agonist (GnRHa) (triptorelin $0.1 \mathrm{mg} / \mathrm{d}$ subcutaneously), starting at the midluteal phase. For $\mathrm{COH}, 225 \mathrm{IE}$ of human menopausal gonadotropin (hMG) was injected daily intramuscularly until the largest follicle cohort had a diameter of 18-20 mm. Ovulation was induced with 10000 IE human chorion gonadotropin (hCG). Five mature ovules were retrieved 35 hours after ovulation by transvaginal puncture and were fertilised. Two blastocysts were transferred. After a positive urine pregnancy test, the presence of an intact singleton pregnancy was recorded in the 6th gestational week (GW).

In the 10 th GW the patient suddenly presented with strong abdominal pain over 24 hours and leukocytosis. The left ovary was enlarged and measured $64 \mathrm{~mm}$ (right ovary $34 \mathrm{~mm}$ ). Laparoscopy found torsion of the left adnexa and polycystic ovaries with cyst rupture. After derotation of the left adnexa ( Fig. 1) and cyst puncture to relieve pressure, the adnexa could be preserved. Postoperative Doppler findings were unremarkable. In the 39th GW she was delivered of a healthy boy, born vaginally, weighing $3860 \mathrm{~g}$ and measuring $51 \mathrm{~cm}$.

\section{Case 2}

A 24-year-old woman with polycystic ovarian syndrome (PCOS), hyperandrogenaemia, and protein $\mathrm{S}$ deficit had had 2 miscarriages in an earlier relationship. Her new partner had grade III oligo-asthenoteratozoospermia syndrome (OAT), making ICSI treatment necessary. Stimulation was done with a GnRHa LP (triptorelin $0.1 \mathrm{mg}$ ) and HMG 150 IE daily, together with metformin tablets $1000 \mathrm{mg}$ and prednisolone tablets $5 \mathrm{mg}$ daily. Eleven metaphase II oocytes were treated by intracytoplasmic morphologically selected sperm injection (IMSI). Fertilisation was confirmed in 7 oocytes. Two blastocysts were transferred, but further cryoconservation was not possible. In the 6th GW the patient

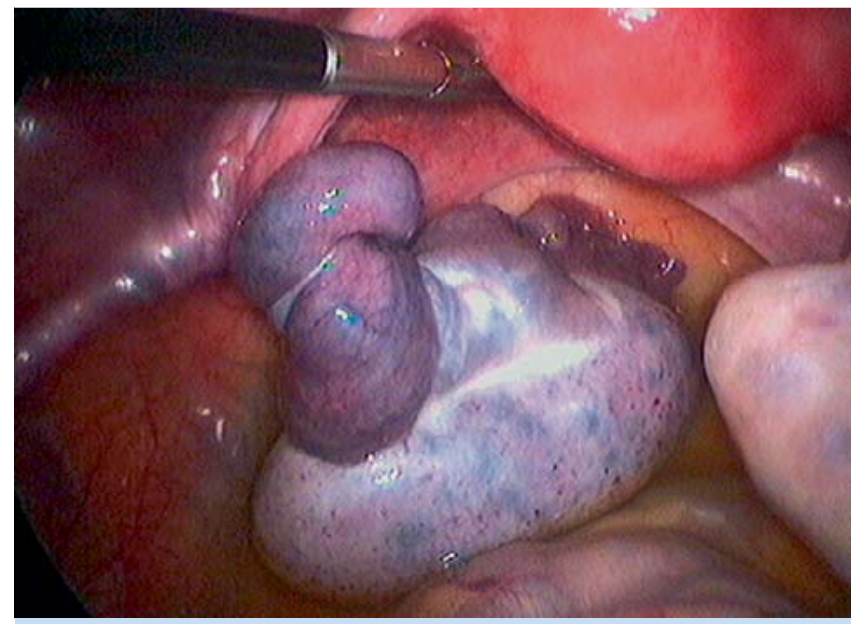

Fig. 1 Laparoscopy: torsion of enlarged left adnexa.

presented with persistent abdominal pain and nausea and increased $\beta$-HCG levels. Sonographically the ovaries were found to be enlarged, measuring 72 and $67 \mathrm{~mm}$, respectively. Laparoscopy confirmed torsion of the right ovary, which was subsequently derotated. The patient was delivered vaginally of a healthy girl $(3175 \mathrm{~g}, 46 \mathrm{~cm})$ born in the $41 \mathrm{st} \mathrm{GW}$.

\section{Case 3}

The husband of a 40-year-old patient had undergone thyroidectomy followed by postoperative radiation therapy 16 years previously for thyroid carcinoma. He subsequently had OAT syndrome. Stimulation of the patient was done in accordance with a GnRHa LP (triptorelin $0.1 \mathrm{mg}$ ) and HMG 300 IE daily. Six of 8 mature oocytes could be fertilised and cultivated until the blastocyst stage. Two blastocysts were transferred. In the 5th GW the patient presented with strong abdominal pain and increased $\beta$-HCG levels. Sonography showed polycystic ovaries (right side $57 \mathrm{~mm}$, left side $52 \mathrm{~mm}$ ). Laparoscopy was indicated as the pain was resistant to analgesia. Both ovaries were enlarged, the right one showed livid discolouration and pelvic peritoneal adhesions. The right ovary was derotated and recovered quickly. Postoperative Doppler ultrasound was unremarkable. In the 10th GW, curettage was required for missed abortion. Eleven months later the patient was delivered of a healthy boy.

\section{Case 4}

A 31-year-old woman underwent IMSI because of asthenoteratozoospermia of her partner. Ten mature oocytes were retrieved after stimulation in accordance with GnRHa LP (triptorelin $0.1 \mathrm{mg}$ ) and HMG stimulation 150 IE daily. Nine oocytes could be fertilised and 1 blastocyst was transferred. Four more blastocysts were cryoconserved. After a positive urine pregnancy test, the patient underwent ultrasound examination for abdominal pain and tympanites. Ultrasound showed enlargement of both ovaries ( $175 \mathrm{~mm}$ on the right, $75 \mathrm{~mm}$ on the left), a 6 -cm left-sided ovarian cyst, free intra-abdominal fluid and an eccentrically located, gestational sac. At this point no surgical intervention was required. In the 8th GW the pain suddenly returned and the torsed right ovary was derotated laparoscopically. In the 19th GW the patient opted for induced abortion because sonography findings showed sirenomelia. 


\section{Case 5}

IMSI was indicated in a 34-year-old woman due to asthenoteratozoospermia of her partner. Stimulation was done in accordance with a GnRHa LP (triptorelin $0.1 \mathrm{mg}$ ) and HMG 225 IE. Eight mature oocytes could be fertilised, 1 blastocyst was transferred, and 2 further blastocysts were cryoconserved. In the 10th GW, the patient suddenly presented with acute abdominal pain. On ultrasound the ovaries were found to be enlarged ( $68 \mathrm{~mm}$ and $48 \mathrm{~mm}$, respectively). Torsion of the right adnexa was found on subsequent laparoscopy. The torsed ovary had ruptured, resulting in bleeding with hematoperitoneum. The adnexa was derotated, coagulation was used to stop the bleeding, and the hematoperitoneum was suctioned off. The adnexa could be preserved and subsequent ultrasound control found the pregnancy to be intact. The subsequent course of the patient's pregnancy was uncomplicated with the exception of gestational diabetes after GW 30. The patient was delivered of a healthy boy weighing $4090 \mathrm{~g}$ in the 40th GW.

\section{Discussion \\ $\nabla$}

\section{Incidence}

The reported incidence of adnexal torsion is $2.3 \%$ in nonpregnant women and $16 \%$ in pregnant women [2]. Adnexal torsion rarely occurs in spontaneous pregnancies (1-5 torsions per 10000 pregnancies). However, $12-25 \%$ of all adnexal torsions occur in pregnant women, often in combination with assisted reproduction and its complications (OHSS). The reported incidence is low for oocyte donation cycles (0-0.2\%) and IVF cycles (0-0.13\%); however, the incidence increased to $6 \%$ under stimulation for ART and to $16 \%$ with OHSS [2-6]. But even when adnexal torsion occurs simultaneously with OHSS, the reported incidence varies between 1 and 33\% [7]. 70\% of torsions occur in multiple pregnancies [8]. The incidence in our study period with 1411 fresh embryo transfers was $0.35 \%$; however, all 5 cases in our study were singleton pregnancies (5/461 births =incidence of $1.08 \%$ per birth after IVF/ICSI) and 2 patients additionally presented with mild OHSS.

\section{Time of occurrence}

The majority of adnexal torsions occur in the 1st or 2nd trimester of pregnancy and only around $10 \%$ occur in the 3rd trimester [2, $10]$. If cysts are found in pregnant women on sonography, these very rarely (3.8\%) result in torsion [6]. According to Mashiach et al., the incidence for both ovaries is approximately the same [2]. In all 5 cases from our ART collective, torsion occurred in pregnant women between the 5th and 10th GW, with 4 torsions found on the right side and 1 on the left side.

\section{Diagnosis}

Symptoms and laboratory parameters

The diagnosis of adnexal torsion is difficult if OHSS is also present because the symptoms are not specific. But late diagnosis increases the risk of having to excise the affected organ. Abdominal pain, nausea and vomiting are often suspicious for torsion. Acute abdominal pain occurs in more than $80 \%$ of cases, often starting suddenly at night and persisting for more than 24 hours [2,9,10, 12].

Several authors have reported that patients had mild leukocytosis; however, while levels may be increased in nonpregnant women, levels may be within normal ranges for pregnant women
$[7,9,12]$. Leukocytosis is also one of the laboratory indicators which may change with OHSS.

\section{Ultrasound diagnosis}

Transvaginal ultrasound may often show enlargement of the ovaries and polycystic changes without this being evidence of torsion. A pathological result of Doppler flow ultrasound may indicate adnexal torsion, but even normal Doppler findings cannot exclude the possibility of torsion. The rate of false-negative Doppler flow results is considerable, with a reported rate of $61 \%$ for pregnant women and $45 \%$ for nonpregnant women [11]. Hasson et al. therefore recommended not to base the decision for surgical evaluation only on the results of Doppler flow investigation (as proposed by Arena et al.) but also to take the patient's past medical history, clinical appearance, and laboratory assessment into account $[11,12]$. The differential diagnosis, particularly for right-sided adnexal torsion, includes appendicitis, renal colic, renal or urethral calculi, and obstructive bowel disease [12]. In all cases in our study, acute abdominal pain or gradually increasing pain, mostly accompanied by enlarged polycystic ovaries, led to the patient being admitted to hospital. The size of the ovary on the affected side in our patients ranged between 57 and $175 \mathrm{~mm}$ (mean $87.2 \mathrm{~mm}$; O Table 1).

\section{Time between hospital admission and surgery}

In the literature, the time between admission to hospital and surgery is between 6 and 15.5 hours and may be even significantly shorter in the 1st trimester of pregnancy. However, several days may pass between the start of symptoms and surgery $[2,13]$. In our cases, acute symptoms or persistence of complaint meant that the mean time to laparoscopic evaluation and treatment was 6.4 hours (1-24 hours), and treatment was still in time to preserve fertility ( $\bullet$ Table 1 ).

\section{Treatment}

Laparoscopic derotation of adnexal torsion is recommended as the first-line treatment, even for ovaries which are already ischaemic, because in $73 \%$ of cases derotation is sufficient to preserve ovarian function. For Arena et al., complete absence of blood flow in the ovarian vessels is an indication for adnexectomy [12]. We were able to avoid adnexectomy in all cases and were therefore able to preserve fertility.

\section{Risk of recurrence}

Laparoscopic fixation of the adnexa (ovariopexy) or shortening of the utero-ovarian ligament can be done to avoid recurrence of adnexal torsion, but this should be the exception rather than the rule [7,14-16]. In their retrospective case control study, Hasson et al. reported a recurrence rate of $19.5 \%$ for pregnant women and $9.1 \%$ for nonpregnant women; however $73.2 \%$ of pregnant women and $20.8 \%$ of nonpregnant women had been treated with ART prior to torsion $[11,17]$. None of the 5 cases in our study experienced recurrence during the subsequent course of their pregnancy.

\section{Outcome}

$\nabla$

Smith et al. reported a reduced fertilisation rate (FR) of $40 \%$ for oocytes aspirated from a derotated ovary, while the FR for the unaffected ovary was $93 \% .75 \%$ of oocytes from the unaffected side and $64 \%$ of oocytes from the affected side developed into blasto- 
Table 1 Summary of 5 cases with adnexal torsion after $\mathrm{COH}$ and ET.

\begin{tabular}{|c|c|c|c|c|c|c|c|c|c|c|c|}
\hline $\begin{array}{l}\text { Age } \\
\text { (years) }\end{array}$ & RO & TE & PR & OHSS & GW & $\begin{array}{l}\text { US: } \\
\text { right } \\
\text { ovary* }\end{array}$ & $\begin{array}{l}\text { US: } \\
\text { left } \\
\text { ovary* }\end{array}$ & $\begin{array}{l}\text { Adm.- } \\
\text { OP }\end{array}$ & Diagnosis & Treatment & Outcome of PR \\
\hline 35 & 5 & 2 & yes & mild & 10 & 38 & 64 & 24 & left adnexal torsion & $\begin{array}{l}\text { laparoscopic de- } \\
\text { torsion + puncture } \\
\text { of ovarian cyst }\end{array}$ & $\begin{array}{l}\text { vaginal delivery, } \\
39 \text { th GW, boy } \\
(2860 \mathrm{~g}, 51 \mathrm{~cm})\end{array}$ \\
\hline 24 & 15 & 2 & yes & no & 6 & 72 & 67 & 1 & right ovarian torsion & $\begin{array}{l}\text { laparoscopic } \\
\text { detorsion }\end{array}$ & $\begin{array}{l}\text { vaginal delivery, } \\
\text { 41st GW, girl } \\
(3175 \mathrm{~g}, 46 \mathrm{~cm})\end{array}$ \\
\hline 40 & 8 & 2 & yes & no & 5 & 57 & 52 & 2 & right ovarian torsion & $\begin{array}{l}\text { laparoscopic } \\
\text { detorsion }\end{array}$ & $\begin{array}{l}\text { missed abortion, } \\
\text { 10th GW, } \\
\text { curettage }\end{array}$ \\
\hline 31 & 13 & 1 & yes & mild & $\begin{array}{l}5 \\
8\end{array}$ & 175 & 75 & 3 & $\begin{array}{l}\text { left ovarian cyst }(6 \mathrm{~cm}) \\
\text { right ovarian torsion }\end{array}$ & $\begin{array}{l}\text { conservative } \\
\text { laparoscopic } \\
\text { detorsion }\end{array}$ & $\begin{array}{l}\text { induced abortion, } \\
\text { 19th GW, } \\
\text { sirenomelia }\end{array}$ \\
\hline 34 & 8 & 1 & yes & no & 10 & 68 & 48 & 2 & $\begin{array}{l}\text { right adnexal torsion, } \\
\text { ovarian rupture, hema- } \\
\text { toperitoneum }\end{array}$ & $\begin{array}{l}\text { laparoscopic de- } \\
\text { torsion + coagula- } \\
\text { tion and suction }\end{array}$ & $\begin{array}{l}\text { vaginal delivery, } \\
\text { 40th GW, boy } \\
(4090 \mathrm{~g}, 56 \mathrm{~cm})\end{array}$ \\
\hline
\end{tabular}

$\mathrm{RO}=$ number of retrieved oocytes, $\mathrm{TE}=$ number of transferred embryos (blastocysts), PR = pregnancy, OHSS = ovarian hyperstimulation syndrome, GW = gestational week at diagnosis, US = ultrasound, ${ }^{*}=$ diameter $(\mathrm{mm})$, Adm.-OP = time between admission to hospital and surgery (hours)

cysts. A reduced FR had been previously described in earlier reports in connection with reduced flow in the ovarian artery [18]. In a repeat IVF procedure, Oelsner et al. retrieved oocytes from laparoscopically derotated ovaries in 6 patients and these oocytes could be subsequently fertilised; Oelsner et al. therefore recommended derotation as the procedure of choice for ischaemic ovaries [19]. The subsequent course of a pregnancy after treatment for adnexal torsion is generally favourable; abortion rates of between $8.3 \%$ and $16.6 \%$ do not appear to be increased $[2,11]$. In our cases, 3 pregnancies continued to term with the vaginal delivery of healthy children. One pregnancy was terminated in the 19th GW for medical reasons as ultrasound showed sirenomelia. There was 1 case of missed abortion in a 40-year-old patient; however 11 months later this patient gave birth to a healthy child.

\section{Conclusion}

Adnexal torsion after ART is not uncommon, particular if accompanied by OHSS and/or (multiple) pregnancy. Adnexal torsion should be kept in mind in patients presenting with acute abdominal pain, nausea, vomiting and sonographically enlarged, polycystic ovaries. The differential diagnosis is difficult, particularly if OHSS is present, and consultation with a reproductive physician should be considered. Laparoscopic investigation and primary derotation should be attempted, even in cases where the organ is already livid and discoloured and Doppler flow is absent. In most cases it will be possible to preserve the affected adnexa and thus preserve fertility.

\section{Conflict of Interest}

The authors declare that they have no financial connections to any company cited in this article.

\section{References}

1 Hibbard LT. Adnexal torsion. Am J Obstet Gynecol 1985;152: 456-461

2 Mashiach S, Bider D, Moran $O$ et al. Adnexal torsion of hyperstimulated ovaries in pregnancies after gonadotropin therapy. Fertil Steril 1990; 53: 76-80

3 Sauer MV. Defining the incidence of serious complications experienced by oocyte donors: a review of 1000 cases. Am J Obstet Gynecol 2001;184: 277-278

4 Maxwell KN, Cholst IN, Rosenwaks Z. The incidence of both serious and minor complications in young women undergoing oocyte donation. Fertil Steril 2008; 90: 2165-2171

5 Bodri D. Complications related to ovarian stimulation and oocyte retrieval in 4052 oocyte donor cycles. Reproductive BioMedicine Online 2008; 17: 237-243

6 Zanetta G, Mariani E, Lissoni A et al. A prospective study of the role of ultrasound in the management of adnexal masses in pregnancy. BJOG 2003; 110: 578-583

7 Rackow B, Patrizio P. Successful pregnancy complicated by early and late adnexal torsion after in vitro fertilization. Fertil Steril 2007; 87: 697-702

8 Wiser A, Levron J, Kreizer D et al. Outcome of pregnancies complicated by severe ovarian hyperstimulation syndrome (OHSS): a follow-up beyond the second trimester. Hum Reprod 2005; 20: 910-914

9 Smorgick N, Barel O, Halperin $R$ et al. Laparoscopic removal of adnexal cysts: is it possible to decrease inadvertent intraoperative rupture rate? Am J Obstet Gynecol 2009; 200: 237.e1-237.e3

10 Mashiach R, Bar-On S, Boyko V et al. Sudden/nocturnal onset of acute abdominal pain, lasting less than a day and accompanied by vomiting: a tell-tale sign of ovarian torsion. Gynecol Surg 2010; 7: 297-301

11 Hasson J, Tsafrir Z, Azem F et al. Comparison of adnexal torsion between pregnant and non-pregnant women. Am J Obstet Gynecol 2010; 202: 536.e1-536.e6

12 Arena S, Canonico S, Luzi G et al. Ovarian torsion in in vitro fertilizationinduced twin pregnancy: combination of Doppler ultrasound and laparoscopy in diagnosis and treatment can quickly solve the case. Fertil Steril 2009; 92: 1496.e9-1496.e13

13 Smorgick N, Pansky M, Feingold $M$ et al. The clinical characteristics and sonographic findings of maternal ovarian torsion in pregnancy. Fertil Steril 2009; 92: 1983-1987

14 Child TJ, Watson NR, Ledger WL. Sequential bilateral adnexal torsion after a single cycle of gonadotropin ovulation induction with intrauterine insemination. Fertil Steril 1997; 67: 573-575

15 Weitzman VN, DiLuigi AJ, Maier DB et al. Prevention of recurrent adnexal torsion. Fertil Steril 2008; 90: 2018.e1-2018.e3 
16 Djavadian D, Braendle W, Jaenicke F. Laparoscopic oophoropexy for the treatment of recurrent torsion of the adnexa in pregnancy: case report and review. Fertil Steril 2004; 82: 933-936

17 Osmanağaoğlu MA, Kesim M, Yuluğ E et al. The effect of high dose methylprednisolone on experimental ovarian torsion/reperfusion injury in rats. Geburtsh Frauenheilk 2012; 72 70-74
18 Smith LP, Oskowitz SP, Barrett B et al. IVF and embryo development subsequent to ovarian torsion occurring during the resumption of meiosis. Reproductive BioMedicine Online 2010; 21: 418-421

19 Oelsner G, Cohen SB, Sorano D et al. Minimal surgery for the twisted ischaemic adnexa can preserve ovarian function. Hum Reprod 2003; 18: $2599-2602$

Deutschsprachige Zusatzinformationen online abrufbar unter: www.thieme-connect.de/ejournals/toc/gebfra. 